\title{
School Environmental Intervention to Reduce Particulate Pollutant Exposures for Children With Asthma
}

\section{Citation}

Jhun, Iny. 2019. School Environmental Intervention to Reduce Particulate Pollutant Exposures for Children With Asthma. Doctoral dissertation, Harvard Medical School.

\section{Permanent link}

http://nrs.harvard.edu/urn-3:HUL.InstRepos:41971489

\section{Terms of Use}

This article was downloaded from Harvard University's DASH repository, and is made available under the terms and conditions applicable to Other Posted Material, as set forth at http:// nrs.harvard.edu/urn-3:HUL.InstRepos:dash.current.terms-of-use\#LAA

\section{Share Your Story}

The Harvard community has made this article openly available.

Please share how this access benefits you. Submit a story.

\section{Accessibility}




\section{Scholarly Report submitted in partial fulfillment of the}

\section{Degree at Harvard Medical School}

Date: 01 March 2019

Student Name: Iny Jhun, ScD

Scholarly Report Title: School Environmental Intervention to Reduce Particulate Pollutant Exposures for Children with Asthma

Mentor Name and Affiliation: Wanda Phipatanakul, MD, MS, Division of Allergy and Immunology, Boston Children's Hospital

\section{Collaborators:}

Jonathan M. Gaffin, MD, MMSc, Division of Respiratory Diseases, Boston Children's Hospital Brent A. Coull, PhD, Department of Biostatistics, Harvard T. H. Chan School of Public Health Michelle F. Huffaker, MD, Division of Allergy and Immunology, Boston Children's Hospital Carter R. Petty, MA, Clinical Research Center, Boston Children's Hospital William J. Sheehan, MD, Division of Allergy and Immunology, Boston Children's Hospital Sachin N. Baxi, MD, Division of Allergy and Immunology, Boston Children's Hospital Peggy S. Lai, MD, Division of Pulmonary and Critical Care, Massachusetts General Hospital Choong-Min Kang, PhD, Department of Environmental Health, Harvard T. H. Chan School of Public Health

Jack M. Wolfson, PhD, Department of Environmental Health, Harvard T. H. Chan School of Public Health

Diane R. Gold, MD, MPH, Channing Division of Network Medicine, Brigham and Women's Hospital Petros Koutrakis, PhD, Department of Environmental Health, Harvard T. H. Chan School of Public Health 


\begin{abstract}
BACKGROUND: Home-based interventions to improve indoor air quality have demonstrated benefits for asthma morbidity, yet little is known about the effect of environmental interventions in the school setting.
\end{abstract}

OBJECTIVE: We piloted the feasibility and effectiveness of a classroom-based air cleaner intervention to reduce particulate pollutants in classrooms of children with asthma.

METHODS: In this pilot randomized controlled trial, we assessed the effect of air cleaners on indoor air particulate pollutant concentrations in 18 classrooms ( 9 control, 9 intervention) in 3 urban elementary schools. We enrolled 25 children with asthma (13 control, 12 intervention) aged 6 to 10 years. Classroom air pollutant measurements and spirometry were completed once before and twice after randomization. Asthma symptoms were surveyed every 3 months.

RESULTS: Baseline classroom levels of fine particulate matter (particulate matter with diameter of $<2.5 \mathrm{~mm}\left[\mathrm{PM}_{2.5}\right]$ ) and black carbon (BC) were 6.3 and $0.41 \mathrm{mg} / \mathrm{m}^{3}$, respectively. When comparing the intervention to the control group, classroom $\mathrm{PM}_{2.5}$ levels were reduced by $49 \%$ and $42 \%$ and BC levels were reduced by $58 \%$ and $55 \%$ in the first and second follow-up periods, respectively ( $\mathrm{P}<.05$ for all comparisons). When comparing the children randomized to intervention and control classrooms, there was a modest improvement in peak flow, but no significant changes in forced expiratory volume in 1 second (FEV1) and asthma symptoms.

CONCLUSIONS: In this pilot study, a classroom-based air cleaner intervention led to significant reductions in $\mathrm{PM}_{2.5}$ and BC. Future large-scale studies should comprehensively evaluate the effect of school-based environmental interventions on pediatric asthma morbidity. 


\section{Contribution}

The air quality monitoring data and health outcomes data had previously been collected. Given my prior research experience in air pollution epidemiology, I processed the previously collected data and performed all the statistical analysis involved in the study, including assessment of the effect of the air cleaner intervention on classroom air quality and health outcomes. I also completed the manuscript write-up and responded to reviewer comments with guidance from my mentor. All collaborators provided comments for the manuscript. I consulted with other biostatisticians in the research group to confirm the statistical methods I utilized and ensure appropriate interpretation of results. Other collaborators were instrumental in collecting the air quality and health outcomes data that I analyzed.

\section{Link}

https://www-ncbi-nlm-nih-gov.ezp-prod1.hul.harvard.edu/pubmed/27641483

\section{Citation}

Jhun I, Gaffin JM, Coull BA, Huffaker MF, Petty CR, Sheehan WJ, Baxi SN, Lai PS, Kang CM, Wolfson JM, Gold DR, Koutrakis P, Phipatanakul W. School Environmental Intervention to Reduce Particulate Pollutant Exposures for Children with Asthma. J Allergy Clin Immunol Pract. 2017 Jan - Feb;5(1):154-159.e3. doi:10.1016/j.jaip.2016.07.018. Epub 2016 Sep 15. PMID: 27641483 


\section{School Environmental Intervention to Reduce Particulate Pollutant Exposures for Children with Asthma}

Iny Jhun, ScD ${ }^{a}$, Jonathan M. Gaffin, MD, MMSc ${ }^{a, b}$, Brent A. Coull, PhD ${ }^{c}$, Michelle F. Huffaker, MD ${ }^{a, d}$, Carter R. Petty, MA ${ }^{e}$, William J. Sheehan, MD ${ }^{a, d}$, Sachin N. Baxi, MD ${ }^{a, d}$, Peggy S. Lai, MD ${ }^{a, f, g}$, Choong-Min Kang, PhD ${ }^{\text {, }}$ Jack M. Wolfson, PhD ${ }^{\mathrm{g}}$, Diane R. Gold, MD, MPH ${ }^{\mathrm{a}, \mathrm{g}, \mathrm{h}}$, Petros Koutrakis, PhD ${ }^{\mathrm{g}}$, and Wanda Phipatanakul, MD, MS ${ }^{\mathrm{a}, \mathrm{d}}$ Boston, Mass

What is already known about this topic? Air cleaner interventions to reduce particulate pollutants at homes have been successful in improving indoor air quality and asthma morbidity in children. However, less is known about the school environment.

What does this article add to our knowledge? This study illustrates the feasibility and efficacy of a school-based air cleaner intervention to reduce classroom particulate pollutants. We found modest evidence of improved lung function.

How does this study impact current management guidelines? Air cleaners can reduce exposures to asthmaexacerbating pollutants present in indoor environments. This supports further evaluation of air cleaners as a classroombased intervention to produce clinically meaningful improvements in asthma morbidity in children.

\footnotetext{
a Harvard Medical School, Boston, Mass

'Division of Respiratory Diseases, Boston Children's Hospital, Boston, Mass

${ }^{c}$ Department of Biostatistics, Harvard T. H. Chan School of Public Health, Boston, Mass

${ }^{\mathrm{d}}$ Division of Allergy and Immunology, Boston Children's Hospital, Boston, Mass

'Clinical Research Center, Boston Children's Hospital, Boston, Mass

${ }^{\mathrm{f}}$ Division of Pulmonary and Critical Care, Massachusetts General Hospital, Boston, Mass

${ }^{\mathrm{g}}$ Department of Environmental Health, Harvard T. H. Chan School of Public Health, Boston, Mass

${ }^{\mathrm{h}}$ Channing Division of Network Medicine, Brigham and Women's Hospital, Boston, Mass

This work was supported by National Institutes of Health (NIH) grant nos. U01 AI 110397, R01 AI 073964, K24 AI 106822, U10 HL 098102, K23 AI 106945, K23 AI 104780, and P03ES000002; National Institute of Environmental Health Sciences (NIEHS) grant no. K23ES023700; and Harvard Medical School Scholars in Medicine Office. This work was conducted with the support from Harvard Catalyst/The Harvard Clinical and Translational Science Center (NIH Award UL1 TR000170) and financial contributions from Harvard University and its affiliated academic health care centers. The content is solely the responsibility of the authors and does not necessarily represent the official views of Harvard Catalyst, Harvard University and its affiliated academic health care centers, the National Center for Research Resources, or the NIH. This work was also supported in part by the American Lung Association, the American Academy of Allergy, Asthma, and Immunology, the Respiratory Diseases Faculty Award, and the Deborah Munroe Noonan Memorial Award. We also thank Coway Co., Ltd, for its funding and for donating the air cleaners used in this study.

Conflicts of interest: D. R. Gold and W. Phipatanakul have been supported by 1 or more grants from the National Institutes of Health. The rest of the authors declare that they have no relevant conflicts of interest.

Received for publication January 22, 2016; revised June 29, 2016; accepted for publication July 25, 2016.

Available online September 15, 2016

Corresponding author: Wanda Phipatanakul, MD, MS, Division of Allergy and Immunology, Boston Children's Hospital, 300 Longwood Ave, Boston, MA 02115. E-mail: wanda.phipatanakul@ childrens.harvard.edu.

2213-2198

(C) 2016 American Academy of Allergy, Asthma \& Immunology

http://dx.doi.org/10.1016/j.jaip.2016.07.018
}

BACKGROUND: Home-based interventions to improve indoor air quality have demonstrated benefits for asthma morbidity, yet little is known about the effect of environmental interventions in the school setting.

OBJECTIVE: We piloted the feasibility and effectiveness of a classroom-based air cleaner intervention to reduce particulate pollutants in classrooms of children with asthma.

METHODS: In this pilot randomized controlled trial, we assessed the effect of air cleaners on indoor air particulate pollutant concentrations in 18 classrooms ( 9 control, 9 intervention) in 3 urban elementary schools. We enrolled 25 children with asthma (13 control, 12 intervention) aged 6 to 10 years. Classroom air pollutant measurements and spirometry were completed once before and twice after randomization. Asthma symptoms were surveyed every 3 months.

RESULTS: Baseline classroom levels of fine particulate matter (particulate matter with diameter of $<2.5 \mu \mathrm{m}\left[\mathrm{PM}_{2.5}\right]$ ) and black carbon (BC) were 6.3 and $0.41 \mu \mathrm{g} / \mathrm{m}^{3}$, respectively. When comparing the intervention to the control group, classroom $\mathrm{PM}_{2.5}$ levels were reduced by $49 \%$ and $42 \%$ and $\mathrm{BC}$ levels were reduced by $58 \%$ and $55 \%$ in the first and second follow-up periods, respectively ( $P<.05$ for all comparisons). When comparing the children randomized to intervention and control classrooms, there was a modest improvement in peak flow, but no significant changes in forced expiratory volume in 1 second $\left(\mathrm{FEV}_{1}\right)$ and asthma symptoms.

CONCLUSIONS: In this pilot study, a classroom-based air cleaner intervention led to significant reductions in $\mathbf{P M}_{2.5}$ and BC. Future large-scale studies should comprehensively evaluate the effect of school-based environmental interventions on 


\author{
Abbreviations used \\ $B C$ - Black carbon \\ HEPA-High efficiency particulate air \\ IPM-Integrated pest management \\ PEF-Peak expiratory flow \\ $P M_{2.5}$ - Particulate matter with diameter of less than $2.5 \mu \mathrm{m}$
}

pediatric asthma morbidity. (C) 2016 American Academy of Allergy, Asthma \& Immunology (J Allergy Clin Immunol Pract 2017;5:154-9)

Key words: Asthma; Indoor air quality; Environmental intervention; Air cleaner

Asthma is one of the most common chronic diseases of childhood in the United States, affecting 13\% of children living in urban areas. ${ }^{1}$ Every year, asthma accounts for more than 10 million missed school days in the United States. ${ }^{1}$ Urban minority populations experience greater asthma morbidity and have higher asthma-related mortality rates. ${ }^{2}$ The relationship between air pollution (eg, fine particulate matter $\left[\mathrm{PM}_{2.5}\right]$ and black carbon $[\mathrm{BC}])$ and asthma morbidity in children is well established. ${ }^{3,4}$ Local and regional traffic pollution are important sources of $\mathrm{PM}_{2.5}$ and $\mathrm{BC}$, which can penetrate indoors and contribute to poor indoor air quality.

In contrast to homes, schools have fewer indoor sources of pollutants, because most schools no longer have active kitchens and smoking is prohibited. However, traffic emissions are an important source, because schools are often centrally located within a community and consequently are closer to heavy traffic routes. In addition, there are many idling cars and buses for pickup and drop-off. Indoor classroom pollutant exposures may be an important risk factor for asthma morbidity in children ${ }^{5}$ because children spend a large portion of their day in school.

Previous studies of home-based environmental interventions using air cleaners have resulted in reduced particulate pollutant exposures and improved asthma symptoms in children. ${ }^{6,7}$ Much less is known about the potential role of classroom-based interventions in improving air quality and asthma morbidity for children. In this study, our primary goal was to pilot the effect of an air cleaner intervention to reduce indoor particulate pollutants in classrooms of children with asthma. Our secondary goal was to determine the effect of reduced pollutant levels on asthma morbidity.

\section{METHODS}

\section{Study population}

We recruited 25 children with asthma, aged 6 to 10 years, from 18 unique classrooms in 3 urban elementary schools in the northeastern United States from 2013 to 2014 (see flow diagram in Figure E1 in this article's Online Repository at www.jaci-inpractice. org). Inclusion and exclusion criteria used in other urban studies were adapted for this study as previously described. ${ }^{8}$ Inclusion criteria included physician-diagnosed asthma for at least 1 year and at least 1 of the following: current daily preventative asthma medication, wheezing in the past year, or an unscheduled medical visit for asthma in the past year. Exclusion criteria included lung disease other than asthma, cardiovascular disease, beta blocker use, and enrollment in another asthma or allergy clinical trial. The study was approved by the local institutional review board and the participating school system. Informed consent was obtained from each participant's parent or legal guardian, and assent was obtained from each participant.

\section{Study recruitment and baseline study visit}

Validated screening survey questionnaires ${ }^{8}$ were distributed in the spring of 2013 to the parents of students to determine eligibility for enrollment (see Figure 1 for study overview). During the summer of 2013, 25 students were enrolled and completed a baseline clinical assessment. This included a baseline demographic, medical, and symptom survey as well as spirometry performed according to American Thoracic Society guidelines 9 (Koko spirometer, Louisville, Colo).

\section{Follow-up questionnaires and school visits}

Follow-up asthma symptom surveys were performed through phone interviews at 3, 6, 9, and 12 months after the baseline visit. Follow-up spirometry was conducted in the fall and spring during school visits.

\section{Exposure assessment}

Environmental exposure assessment for indoor $\mathrm{PM}_{2.5}, \mathrm{BC}$, and settled dust allergen levels was completed at baseline before randomization and twice during the academic year (once in the winter and once in the spring). Air sampling for $\mathrm{PM}_{2.5}$ and $\mathrm{BC}$ concentration was performed by placing personal exposure monitors $1.5 \mathrm{~m}$ above the floor in each classroom for 1 week, as far away from the air cleaner exhaust as possible. Sampling devices were set to an automatic timer that turned off after school and turned on when school started to restrict measurements to school hours. Each personal exposure monitor includes an inertial impactor (H-PEM, BGI Inc, Waltham, Mass) ${ }^{10}$ to collect $\mathrm{PM}_{2.5}$ on $37-\mathrm{mm}$ Teflon membrane filters at a flowrate of $1.8 \mathrm{~L} / \mathrm{min}$. The Teflon filters were weighed before and after sample collection on an electronic microbalance (MT-5 Mettler Toledo, Columbus, Ohio). Indoor BC concentrations were measured by the reflectance method on the collected Teflon filters using a smoke stain reflectometer (model EEL M43D, Diffusion Systems Ltd, London, United Kingdom).

Classroom settled dust samples were collected using a hand-held vacuum with a special dust collector (DACI Lab, Johns Hopkins, Baltimore, Md) using a standardized protocol. ${ }^{11}$ For each sample, standardized vacuum sampling was performed for 3 minutes on the floor and 3 minutes on desk/chair surfaces. Dust samples were analyzed using a multiplex array for indoor allergens (MARIA, Indoor Biotechnologies, Charlottesville, Va) ${ }^{12}$ that simultaneously measured the following allergens: cockroach (Bla g 2), cat (Fel d 1), $\operatorname{dog}(\operatorname{Can} \mathrm{f} 1$ ), mouse (Mus m 1), and dust mite (Der f 1).

\section{Intervention}

Eighteen classrooms (for the 25 participants) were randomized in a 1:1 ratio by school to receive high efficiency particulate air (HEPA) cleaners. This resulted in 9 intervention classrooms with 12 children and 9 control classrooms with 13 children. We used a commercial air cleaner (AP-1013A, Coway, Seoul, Korea) with a HEPA filter. A total of 4 air cleaners were placed on the floor in each intervention classroom in the same position throughout the study period: near the hallway, next to windows, and front and back of the classroom. To achieve a minimal impact on classroom activities, each air cleaner was adjusted to a noise level of $50 \mathrm{~dB}$, corresponding to an air delivery rate of $3.7 \mathrm{~m}^{3} / \mathrm{min}$. For the control group, sham air cleaners were constructed by removing the filters and adding a sound 


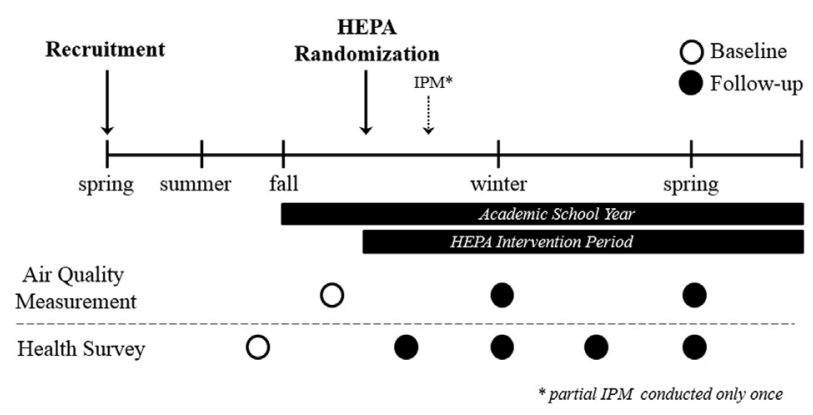

FIGURE 1. Study design schema. A total of 18 classrooms (25 students) in 3 schools were randomized to an air cleaner intervention or a sham filter control. Six classrooms from 1 school also received IPM in the fall. Baseline study visits were completed before the start of school. Baseline classroom pollutant levels were measured during the fall semester before randomization.

generator (Zohne, Marpac, Wilmington, NC). In a blind test, the noise level of each sham air cleaner was adjusted to the same level as that of an active air cleaner. The children, teachers, and school officials were blinded to the status (active vs sham) of the air cleaners in each classroom. Because the recommended time for replacing the HEPA filter is 12 months, we did not change the filter during the study period.

Simultaneously, we also piloted the feasibility of an integrated pest management (IPM) intervention in these schools. Because of limited resources, a partial IPM was conducted once in the fall semester for 6 classrooms from 1 school. The IPM consisted of vacuuming and filling holes and cracks with copper mesh and caulk sealant.

\section{Asthma symptoms and lung function}

Frequency of asthma symptoms was based on caregiver responses to the questions about daytime and nighttime symptoms in the past 2 weeks, and interference with the child's activities in the past 2 weeks was based on a validated questionnaire. ${ }^{8}$ Experiencing any of the above symptoms was considered as having an "any symptom" day, a dichotomous metric that has been used in other asthma studies. ${ }^{13}$ Spirometry was completed at baseline and 2 follow-up visits, and results reviewed for quality by a pediatric pulmonologist. ${ }^{14}$ Spirometry results were analyzed only in participants with a valid baseline measurement and at least 1 valid follow-up measurement.

\section{Statistical analysis}

Summary statistics were computed for demographic characteristics and baseline air quality and asthma morbidity outcomes. For the primary outcome (classroom $\mathrm{PM}_{2.5}$ and $\mathrm{BC}$ levels), linear mixedeffects models were applied to account for correlation due to repeated measures, with classroom-specific random intercepts to allow baseline pollutant levels to vary by classroom (for more details, see Appendix in this article's Online Repository at www.jaciinpractice.org). Baseline pollutant levels were compared between the intervention and control classrooms in each school using the Wilcoxon rank-sum test. Dust allergen levels were evaluated using a similar model with log-transformed allergen levels, given their lognormal distribution. Baseline allergen levels were compared between the intervention and control groups using the Wilcoxon ranksum test.
TABLE I. School and classroom characteristics

\begin{tabular}{|c|c|c|c|}
\hline Characteristic & A & B & C \\
\hline Year built & 1975 & 1959 & 1969 \\
\hline \multicolumn{4}{|l|}{ Classrooms (n) } \\
\hline Control & 4 & 2 & 3 \\
\hline Intervention & 4 & 2 & 3 \\
\hline \multicolumn{4}{|l|}{ Students (n) } \\
\hline Control & 5 & 2 & 5 \\
\hline Intervention & 6 & 3 & 4 \\
\hline \multicolumn{4}{|c|}{$\begin{array}{l}\text { Classroom floor, } \\
\text { median (range) }\end{array}$} \\
\hline Control & $3(1-4)$ & $0(0-0)$ & $2(2-2)$ \\
\hline Intervention & $3.5(2-4)$ & $0.5(0-1)$ & $2(2-2)$ \\
\hline \multicolumn{4}{|c|}{$\begin{array}{l}\text { Classrooms facing } \\
\text { drop-off/pick-up } \\
\text { area }(n)\end{array}$} \\
\hline Control & 2 & 0 & 0 \\
\hline Intervention & 2 & 2 & 0 \\
\hline \multicolumn{4}{|c|}{$\mathrm{PM}_{2.5}$, mean (range) } \\
\hline Control & $5.8(5.7-6.1)$ & $6.9(6.6-7.2)$ & $6.7(6-7.3)$ \\
\hline Intervention & $5.5(4.8-5.9)$ & $7.1(6.8-7.5)$ & $6.2(5.1-6.8)$ \\
\hline \multicolumn{4}{|c|}{$\mathrm{BC}$, mean (range) } \\
\hline Control & $0.47(0.4-0.55)$ & $0.28(0.14-0.42)$ & $0.41(0.33-0.47)$ \\
\hline Intervention & $0.39(0.31-0.52)$ & $0.34(0.28-0.4)$ & $0.48(0.45-0.51)$ \\
\hline
\end{tabular}

For the secondary outcomes, linear mixed-effects models similar to the aforementioned model were used to estimate the effect of the intervention on lung function (eg, forced expiratory volume in 1 second $\left[\mathrm{FEV}_{1}\right]$ and peak expiratory flow $\left.[\mathrm{PEF}]\right)$. An analogous generalized mixed-effects model was used to evaluate the effect of the intervention on the presence or absence of asthma symptoms in the previous 2 -week period. Subject-specific random intercepts were included in these models. All analyses were performed using SAS (version 9.2; SAS Institute, Cary, NC). A $P$ value of less than .05 was considered statistically significant.

\section{RESULTS}

\section{School and classroom characteristics}

We recruited participants from 18 classrooms in 3 urban inner-city elementary schools in the United States (Table I). The schools were built in 1959 to 1975 , and the oldest school did not have a central heating, ventilating, air conditioning system. The classrooms were randomized to the control group and the intervention group in a 1:1 ratio within each school. Classroom floor level and number of classrooms facing the drop-off/pick-up area were comparable between the control and intervention groups in each school. At baseline, there were no statistically significant differences between the control and intervention classrooms within each school for both $\mathrm{PM}_{2.5}$ and BC.

\section{Baseline participant characteristics}

A total of 25 children were enrolled in the study (see flow diagram in Figure E1). Children in the treatment and control groups had similar sociodemographic and health characteristics (Table II). The mean age of children was 8.1 years (range, 6.010.9 years) and $60 \%$ were female. Most children identified as black $(60 \%)$ or Hispanic (24\%), with $80 \%$ percent having Medicaid as their primary health insurance. 
TABLE II. Baseline sociodemographic and health characteristics by group

\begin{tabular}{|c|c|c|}
\hline Characteristic & $\begin{array}{l}\text { Control group } \\
(\mathrm{n}=12)\end{array}$ & $\begin{array}{l}\text { Air cleaner group } \\
(\mathrm{n}=13)\end{array}$ \\
\hline Girls, n (\%) & $7(58)$ & $8(62)$ \\
\hline Age $(y)$, mean $\pm S D$ & $8.4 \pm 1.5$ & $7.8 \pm 1.2$ \\
\hline \multicolumn{3}{|l|}{ Race, n (\%) } \\
\hline Black & $7(58)$ & $8(62)$ \\
\hline Hispanic & $2(17)$ & $4(31)$ \\
\hline Other & $3(25)$ & $1(8)$ \\
\hline Medicaid, n (\%) & $8(67)$ & $12(92)$ \\
\hline $\begin{array}{l}\text { Family history of } \\
\text { asthma, } \mathrm{n}(\%)\end{array}$ & $10(83)$ & $10(77)$ \\
\hline $\begin{array}{c}\text { Home tobacco smoke } \\
\text { exposure, } \mathrm{n}(\%)\end{array}$ & $3(25)$ & $3(23)$ \\
\hline $\begin{array}{l}\text { Asthma controller medication } \\
\text { use, } \mathrm{n}(\%)\end{array}$ & $11(92)$ & $12(92)$ \\
\hline
\end{tabular}

At baseline, $44 \%$ of the children reported daytime asthma symptoms in the previous 2 weeks (mean, 1.5 of 14 days), 20\% reported nighttime asthma symptoms (mean, 1.0 of 14 days), and $48 \%$ reported asthma-related interference with activities (mean, 1.2 of 14 days). In addition, $92 \%$ of the children took daily controller medications. Of note, $80 \%$ of the children had a family history of asthma. Spirometry measurements were valid in 16 participants. Baseline $\mathrm{FEV}_{1}$ percent predicted was $88 \% \pm 12 \%$, and PEF was $3.0 \pm 0.8 \mathrm{~L} / \mathrm{s}$.

\section{Classroom pollutant levels}

Before randomization, baseline mean \pm SD classroom levels of $\mathrm{PM}_{2.5}$ and $\mathrm{BC}$ were $6.3 \pm 0.8$ and $0.41 \pm 0.10 \mu \mathrm{g} / \mathrm{m}^{3}$, respectively. There were no differences in $\mathrm{PM}_{2.5}$ and $\mathrm{BC}$ levels between the control and intervention classrooms $\left(\mathrm{PM}_{2.5}\right.$, $P=.63$; BC, $P=0.92$ ).

In the control group, mean $\mathrm{PM}_{2.5}$ concentrations decreased from $6.4 \pm 0.6 \mu \mathrm{g} / \mathrm{m}^{3}$ at baseline to $4.8 \pm 1.1$ and $5.0 \pm 0.8 \mu \mathrm{g} /$ $\mathrm{m}^{3}$ at the first and second follow-up visits, respectively. In the intervention group, mean $\mathrm{PM}_{2.5}$ concentrations decreased from $6.2 \pm 0.9 \mu \mathrm{g} / \mathrm{m}^{3}$ at baseline to $2.4 \pm 0.6$ and $2.6 \pm 1.0 \mu \mathrm{g} / \mathrm{m}^{3}$ at the first and second follow-up visits, respectively. The intervention group had greater reductions in $\mathrm{PM}_{2.5}$ levels compared with the control group by $2.3 \mu \mathrm{g} / \mathrm{m}^{3}$ (95\% CI, -3.5 to -1.0 ; $P=.003)$ at the first follow-up and $2.2 \mu \mathrm{g} / \mathrm{m}^{3}$ (95\% CI, -3.4 to $-1.1 ; P=.002)$ at the second follow-up, which correspond to a $49 \%$ and $42 \%$ reduction, respectively (Figure 2).

In the control group, mean BC concentrations decreased from $0.41 \pm 0.12 \mu \mathrm{g} / \mathrm{m}^{3}$ at baseline to $0.30 \pm 0.21$ and $0.33 \pm 0.12$ $\mu \mathrm{g} / \mathrm{m}^{3}$ at the first and second follow-up visits, respectively. In the intervention group, mean BC concentrations decreased from $0.41 \pm 0.09 \mu \mathrm{g} / \mathrm{m}^{3}$ at baseline to $0.13 \pm 0.07$ and $0.15 \pm 0.12$ $\mu \mathrm{g} / \mathrm{m}^{3}$ at the first and second follow-up visits, respectively. The intervention group had greater reductions in BC levels compared with the control group by $0.17 \mu \mathrm{g} / \mathrm{m}^{3}$ (95\% CI, -0.32 to $-0.03 ; P=.03)$ at the first follow-up and $0.19 \mu \mathrm{g} / \mathrm{m}^{3}(95 \%$ CI, -0.32 to $-0.05 ; P=.001)$ at the second follow-up, which correspond to a $58 \%$ and $55 \%$ reduction, respectively. The $\mathrm{PM}_{2.5}$ and $\mathrm{BC}$ reductions achieved by the air cleaner intervention were comparable between schools (see Table E1 in this article's Online Repository at www.jaci-inpractice.org).

\section{Allergen levels}

Baseline mouse allergen (Mus m 1) levels ranged from 0.04 to $25.5 \mu \mathrm{g} / \mathrm{g}$. The partial IPM intervention did not show an effect on Mus $\mathrm{m} 1$ levels and other allergens. Of note, the baseline Mus m 1 levels were significantly lower in the 6 classrooms that received IPM than in the 12 classrooms that did not receive IPM $(P=.004)$. In the control group, median Mus m 1 levels were $3.3 \mu \mathrm{g} / \mathrm{g}$ (range, $0.4-25.5 \mu \mathrm{g} / \mathrm{g}$ ) at baseline and $0.7 \mu \mathrm{g} / \mathrm{g}$ (range, $0.2-8.4 \mu \mathrm{g} / \mathrm{g}$ ) and $16.4 \mu \mathrm{g} / \mathrm{g}$ (range, 0.05-54.5 $\mu \mathrm{g} / \mathrm{g}$ ) at the first and second follow-up visits, respectively. In the intervention group, median Mus m 1 levels were $0.1 \mu \mathrm{g} / \mathrm{g}$ (range, $0.04-1.4 \mu \mathrm{g} / \mathrm{g}$ ) at baseline and $0.5 \mu \mathrm{g} / \mathrm{g}$ (range, $0.1 \mu \mathrm{g} / \mathrm{g}$ 0.8 ) and $0.3 \mu \mathrm{g} / \mathrm{g}$ (range, $0.1-1.5 \mu \mathrm{g} / \mathrm{g}$ ) at the first and second follow-up visits, respectively. There were minimal changes in the other allergens.

\section{Symptoms}

At baseline, $52 \%$ of the children reported asthma symptoms in the previous 2 weeks. Six months after randomization, $23 \%$ (3 out of 13) of children in the intervention group and 33\% (4 out of 12) of children in the control group reported asthma symptoms. During the trial, the proportion of children reporting asthma symptoms was slightly lower in the intervention group than in the control group, but these differences were not statistically significant (see Figure E2 in this article's Online Repository at www.jaci-inpractice.org). Out of 25 children, 16 had spirometry measurements suitable for analyses. There were no differences in baseline $\mathrm{FEV}_{1}$ and PEF between children in the control and intervention groups. The intervention group had a greater improvement in PEF compared with the control group by $0.46 \mathrm{~L} / \mathrm{s}(95 \% \mathrm{CI}, 0.09-0.83 ; P=.03)$ at the first follow-up, which corresponds to a $16 \%$ improvement. There were no differences in other measures of lung function between the intervention and control groups.

\section{DISCUSSION}

In this pilot study, we demonstrated that a classroom-based air cleaner intervention significantly reduced classroom levels of 2 important indoor particulate pollutants; $\mathrm{PM}_{2.5}$ and $\mathrm{BC}$. Importantly, these reduced pollutant levels were sustained throughout the academic year in the intervention group in all schools. There was modest evidence of improvement in lung function and asthma symptoms in participants of the intervention classrooms. It is well established that exposures to air pollutants increase asthma morbidity in children. ${ }^{3}$ Previous home-based studies have used air cleaners to improve indoor air quality and assess asthma symptoms in children, ${ }^{6,7}$ but there are no studies on the efficacy of an air cleaner intervention in schools.

In the intervention classrooms, $\mathrm{PM}_{2.5}$ and $\mathrm{BC}$ levels were significantly reduced compared with the control classrooms that received a sham air filter. The air cleaner intervention reduced $\mathrm{PM}_{2.5}$ and BC levels by up to $49 \%$ and $58 \%$, respectively. These reductions were within the range of previously reported air cleaner removal efficacy of indoor particulate pollutants. $7,13,15$ Eggleston et $\mathrm{al}^{13}$ demonstrated that an air cleaner intervention in homes led to a significant decrease in room $\mathrm{PM}_{2.5}$ levels from 38 to $24 \mu \mathrm{g} / \mathrm{m}^{3}$ over 12 months. Butz et $\mathrm{al}^{7}$ found a similar effect, with a decrease in room $\mathrm{PM}_{2.5}$ levels from 34 to $18 \mu \mathrm{g} / \mathrm{m}^{3}$ at 6 months. Most homes in these studies had smokers at home, which leads to higher $\mathrm{PM}_{2.5}$ levels compared with the average 
$\mathrm{PM}_{2.5}$

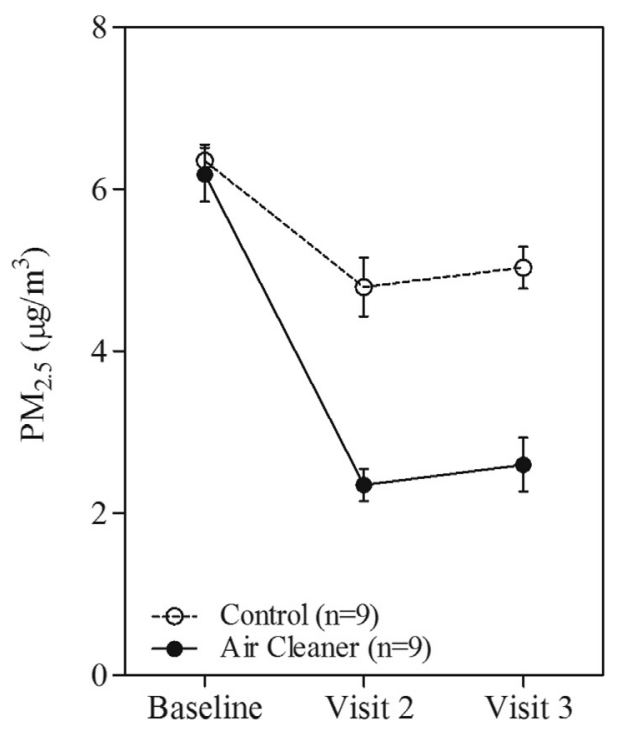

BC

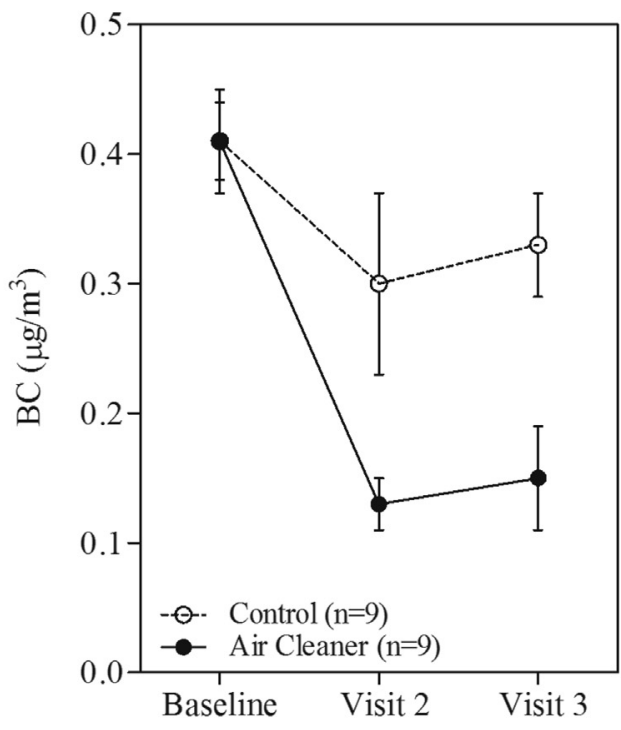

FIGURE 2. Classroom particulate pollutant levels. Classroom $P M_{2.5}\left(\mu \mathrm{g} / \mathrm{m}^{3}\right)$ and $B C\left(\mu \mathrm{g} / \mathrm{m}^{3}\right)$ levels at baseline and follow-up visits in the intervention and control groups. Mean and standard errors shown.

classroom $\mathrm{PM}_{2.5}$ level of $6 \mu \mathrm{g} / \mathrm{m}^{3}$ in our study - a concentration far below the Environmental Protection Agency standard of $35 \mu \mathrm{g} / \mathrm{m}^{3}$ for daily outdoor $\mathrm{PM}_{2.5}$. Even though classroom $\mathrm{PM}_{2.5}$ levels were lower, the air cleaners achieved similar particle removal effectiveness as the home-based studies. In addition, the low pollutant levels were sustained throughout the school year in the intervention group. This study focused on particulate pollutants, which are more effectively removed by HEPA cleaners, than on gaseous pollutants, such as ozone and nitrogen dioxide. Furthermore, in schools where there are no active kitchens and smoking is prohibited, there are minimal indoor sources of gaseous pollutants.

The decreases in $\mathrm{PM}_{2.5}$ and $\mathrm{BC}$ in the intervention group were within the range that has been associated with significant changes in lung function and asthma symptoms in previous epidemiological studies. ${ }^{5,16,17}$ Many previous intervention studies have measured $\mathrm{PM}_{2.5}$, but not $\mathrm{BC}$. $\mathrm{BC}$ is a marker of local and regional traffic pollutants and measured as the lightabsorbing component of particulate matter. BC exposure is associated with airway inflammation, ${ }^{18}$ and time-series studies have found significant effects of BC exposure on pediatric asthma hospital admissions. ${ }^{4}$ Furthermore, exposure to BC has been associated with decreased cognitive function and attention in urban children. ${ }^{19-21}$ This further makes reducing BC desirable in the classroom setting. Because the pollutant levels in our study were lower than noted in similar home-based studies, it will be important to determine in larger cohort studies whether changes in low-level exposures have clinically relevant impact.

In addition to the air cleaner intervention, we aimed to demonstrate the feasibility of implementing an IPM intervention in the school setting. The IPM intervention is expected to be more effective in reducing settled dust allergens than the air cleaners, which remove airborne particles. In previous studies, we have demonstrated that school mouse allergen levels were consistently higher compared with levels in homes of children with asthma. ${ }^{22,23}$ We also previously demonstrated the efficacy of a home-based IPM intervention in reducing dust mouse allergens when performed multiple times over several months. ${ }^{24}$ Because of limited resources, we were able to implement only a partial IPM in 6 classrooms from the same school and only once during the fall. Furthermore, by chance, the classrooms assigned to receive IPM had significantly lower mouse allergen levels at baseline compared with the classrooms that did not receive IPM. Given these limitations, we were unable to assess the efficacy of the IPM intervention on dust mouse allergen levels, but demonstrated that the IPM can be feasibly conducted as part of an environmental intervention strategy in schools.

Small sample size limits the interpretation of the health outcomes, which were secondary outcomes of interest in this study. However, we were encouraged in this pilot to observe modest improvements in lung function. A 16\% improvement in PEF was observed at the first follow-up. Despite known limitations of peak flow data, studies have shown that PEF measures capture lung function decrements associated with clinically important asthma symptoms in children. ${ }^{25}$ We did not observe any differences in the second follow-up. One possibility is that children spend more time outdoors during the warmer months (MayJune), which may reduce the efficacy of improvement in indoor air quality. A larger study is needed to verify these relationships. Although we did not detect differences in asthma symptoms in this pilot, some evidence of improvement was noted.

This study has other additional limitations. We did not measure classroom ventilation (air exchange) rate, which is an important determinant of indoor particulate pollutant levels. Greater ventilation (ie, opening windows) may increase particulate pollutants infiltrating from outdoors. Therefore, potential differences between ventilation rates in intervention and control classrooms could affect estimates of the air cleaner effectiveness. Because baseline particulate pollutant levels were very close between the intervention and control groups, ventilation rates were likely similar with minimal impact on our results.

Our pilot study demonstrates that an air cleaner intervention in classrooms can be effective in reducing particulate pollutants 
in inner-city schools, and that an integrated air cleaner and IPM intervention can be implemented in a school setting. With the exception of work in public housing, most previous studies have focused on environmental remediation for individual children with asthma in single homes. The school environment can be considered as an efficient target for reduction of asthma morbidity because classroom/school-based interventions may reduce exposures for many children in a community. Further large-scale studies are needed to comprehensively evaluate the effectiveness of school-based environmental interventions in reducing asthma morbidity in children.

\section{REFERENCES}

1. Keet CA, McCormack MC, Pollack CE, Peng RD, McGowan E, Matsui EC. Neighborhood poverty, urban residence, race/ethnicity, and asthma: Rethinking the inner-city asthma epidemic. J Allergy Clin Immunol 2015;135:655-62.

2. Price JH, Khubchandani J, McKinney M, Braun R. Racial/ethnic disparities in chronic diseases of youths and access to health care in the United States. Biomed Res Int 2013;2013:787616.

3. Zheng X-Y, Ding H, Jiang L-N, Chen S-W, Zheng J-P, Qiu M, et al. Association between air pollutants and asthma emergency room visits and hospital admissions in time series studies: a systematic review and meta-analysis. PLoS One 2015;10:e0138146.

4. Hua J, Yin Y, Peng L, Du L, Geng F, Zhu L. Acute effects of black carbon and $\mathrm{PM}_{2.5}$ on children asthma admissions: a time-series study in a Chinese city. Sci Total Environ 2014;481:433-8.

5. Habre R, Moshier E, Castro W, Nath A, Grunin A, Rohr A, et al. The effects of $\mathrm{PM}_{2.5}$ and its components from indoor and outdoor sources on cough and wheeze symptoms in asthmatic children. J Expo Sci Environ Epidemiol 2014;24:380-7.

6. Lanphear BP, Hornung RW, Khoury J, Yolton K, Lierl M, Kalkbrenner A. Effects of HEPA air cleaners on unscheduled asthma visits and asthma symptoms for children exposed to secondhand tobacco smoke. Pediatrics 2011;127:93-101.

7. Butz A, Matsui E, Breysse P, Curtin-Brosnan J, Eggleston P, Diette G, et al. A randomized trial of air cleaners and a health coach to improve indoor air quality for inner-city children with asthma and secondhand smoke exposure. Arch Pediatr Adolesc Med 2011;165:741-8.

8. Phipatanakul W, Bailey A, Hoffman EB, Sheehan WJ, Lane JP, Baxi S, et al. The school inner-city asthma study: design, methods, and lessons learned. J Asthma 2011;48:1007-14.

9. Miller MR, Hankinson J, Brusasco V, Burgos F, Casaburi R, Coates A, et al. Standardisation of spirometry. Eur Respir J 2005;26:319-38.

10. Demokritou P, Kavouras IG, Ferguson ST, Koutrakis P. Development and laboratory performance evaluation of a personal multipollutant sampler for simultaneous measurements of particulate and gaseous pollutants. Aerosol Sci Technol 2001;35:741-52.
11. Mitchell H, Senturia Y, Gergen P, Baker D, Joseph C, McNiff-Mortimer K, et al. Design and methods of the National Cooperative Inner-City Asthma Study. Pediatr Pulmonol 1997;24:237-52.

12. King EM, Filep S, Smith B, Platts-Mills T, Hamilton RG, Schmechel D, et al. A multi-center ring trial of allergen analysis using fluorescent multiplex array technology. J Immunol Methods 2013;387:89-95.

13. Eggleston PA, Butz A, Rand C, Curtin-Brosnan J, Kanchanaraksa S, Swartz L, et al. Home environmental intervention in inner-city asthma: a randomized controlled clinical trial. Ann Allergy Asthma Immunol 2005;95:518-24.

14. Miller MR, Hankinson J, Brusasco V, Burgos F, Casaburi R, Coates A, et al. Standardisation of spirometry. Eur Respir J 2005;26:319-38.

15. Du L, Batterman S, Parker E, Godwin C, Chin J-Y, O'Toole A, et al. Particle concentrations and effectiveness of free-standing air filters in bedrooms of children with asthma in Detroit, Michigan. Build Env 2011;46:2303-13.

16. Rice MB, Ljungman PL, Wilker EH, Gold DR, Schwartz JD, Koutrakis P, et al. Short-term exposure to air pollution and lung function in the Framingham Heart Study. Am J Respir Crit Care Med 2013;188:1351-7.

17. Zora JE, Sarnat SE, Raysoni AU, Johnson BA, Li W-W, Greenwald R, et al. Associations between urban air pollution and pediatric asthma control in El Paso, Texas. Sci Total Environ 2013;448:56-65.

18. De Prins S, Dons E, Van Poppel M, Int Panis L, Van de Mieroop E, Nelen V, et al. Airway oxidative stress and inflammation markers in exhaled breath from children are linked with exposure to black carbon. Environ Int 2014;73: 440-6.

19. Chiu YM, Bellinger DC, Coull BA, Anderson S, Barber R. Associations between traffic-related black carbon exposure and attention in a prospective birth cohort of urban children. Environ Health Perspect 2013;121:859-64.

20. Forns J, Dadvand P, Foraster M, Alvarez-Pedrerol M, Rivas I, LópezVicente M, et al. Traffic-related air pollution, noise at school, and behavioral problems in Barcelona schoolchildren: a cross-sectional study. Environ Health Perspect 2016;124:529-35.

21. Dadvand P, Nieuwenhuijsen MJ, Esnaola M, Forns J, Basagaña X, AlvarezPedrerol M, et al. Green spaces and cognitive development in primary schoolchildren. PNAS 2015;112:7937-42.

22. Permaul P, Sheehan WJ, Baxi SN, Gaffin JM, Fu C, Petty CR, et al. Predictors of indoor exposure to mouse allergen in inner-city elementary schools. Ann Allergy Asthma Immunol 2013;111:299-301.e1.

23. Sheehan WJ, Rangsithienchai PA, Muilenberg ML, Rogers CA, Lane JP, Ghaemghami J, et al. Mouse allergens in urban elementary schools and homes of children with asthma. Ann Allergy Asthma Immunol 2009;102:125-30.

24. Phipatanakul W, Cronin B, Wood RA, Eggleston PA, Shih M-C, Song L, et al. Effect of environmental intervention on mouse allergen levels in homes of inner-city Boston children with asthma. Ann Allergy Asthma Immunol 2004;92: 420-5.

25. Meltzer EO, Pearlman DS, Eckerwall G, Uryniak T, DePietro M, Lampl K. Efficacy and safety of budesonide administered by pressurized metered-dose inhaler in children with asthma. Ann Allergy Asthma Immunol 2015;115: 516-22. 


\section{APPENDIX}

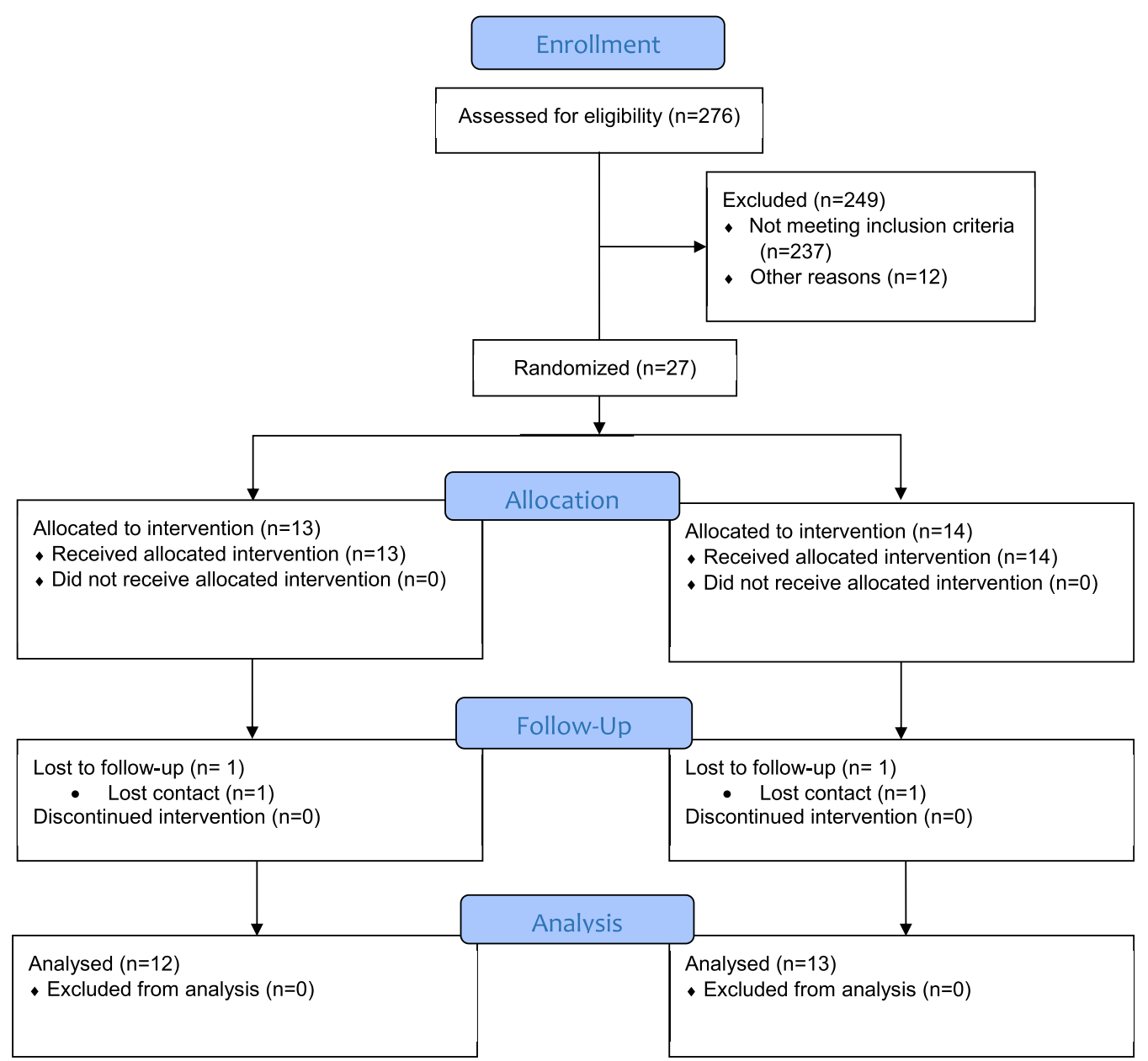

FIGURE E1. Study participant flow CONSORT diagram. 

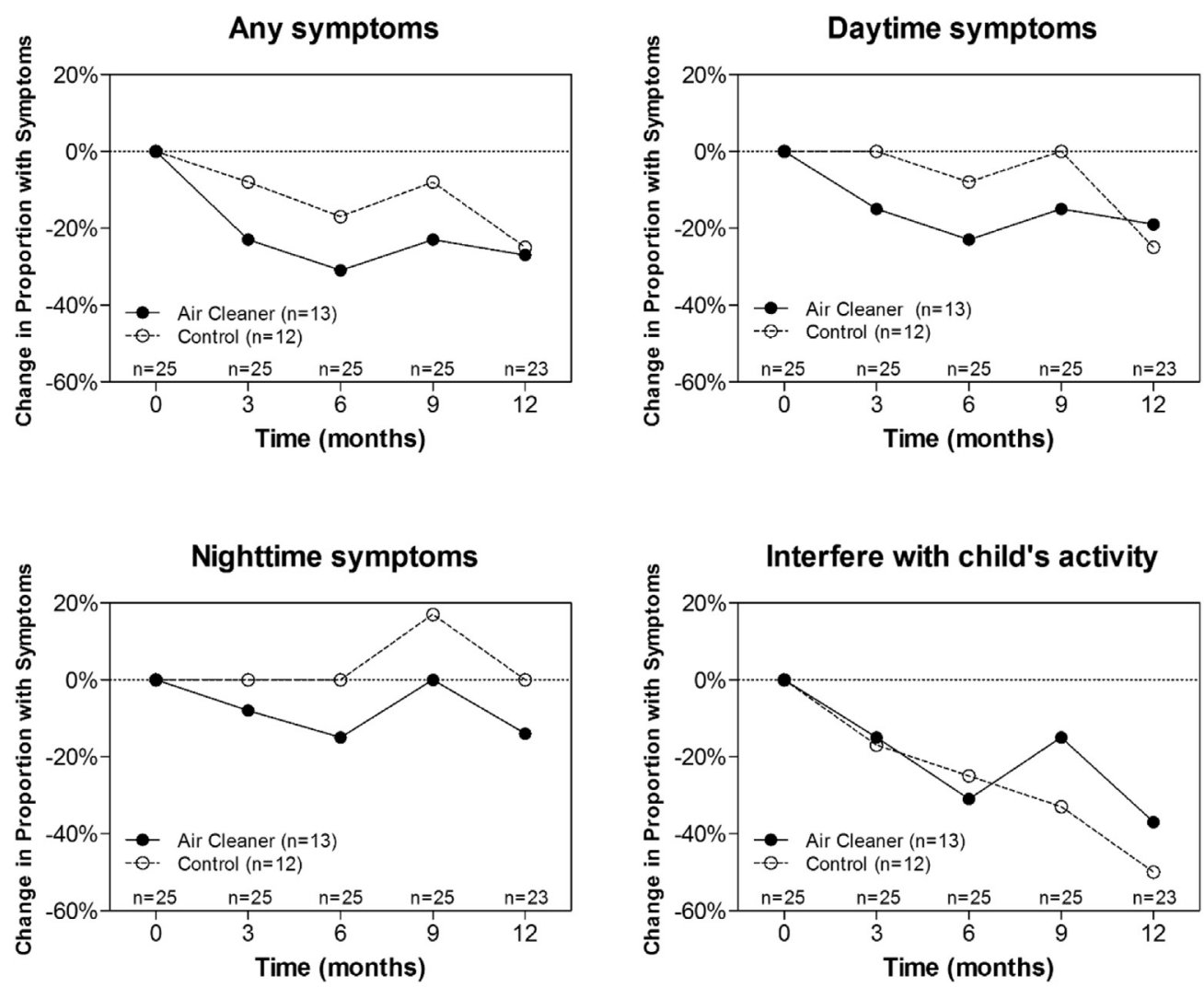

FIGURE E2. Asthma symptoms in the intervention and control groups. Proportion of children reporting asthma symptoms in the past 2 weeks (in \%). Any symptoms include daytime symptoms, nighttime symptoms, or interference with activity within the past 2 weeks. 
TABLE E1. $\mathrm{PM}_{2.5}$ and $\mathrm{BC}$ concentrations by school

\begin{tabular}{|c|c|c|c|c|c|c|}
\hline \multirow[b]{2}{*}{ School } & \multirow[b]{2}{*}{ Group } & \multirow[b]{2}{*}{ Visit } & \multicolumn{2}{|c|}{$\mathrm{PM}_{2.5}$} & \multicolumn{2}{|c|}{ BC } \\
\hline & & & Mean & Range & Mean & Range \\
\hline \multirow[t]{6}{*}{ A } & Control & Baseline & 5.8 & $5.7-6.1$ & 0.47 & $0.4-0.55$ \\
\hline & & Visit 2 & 5.6 & $4.8-6.5$ & 0.49 & $0.38-0.57$ \\
\hline & & Visit 3 & 4.9 & $4.4-5.5$ & 0.39 & $0.21-0.47$ \\
\hline & Intervention & Baseline & 5.5 & $4.8-5.9$ & 0.39 & $0.31-0.52$ \\
\hline & & Visit 2 & 2.7 & $1.8-3.6$ & 0.17 & $0.11-0.24$ \\
\hline & & Visit 3 & 3.2 & $2.2-4.4$ & 0.22 & $0.15-0.38$ \\
\hline \multirow[t]{6}{*}{ B } & Control & Baseline & 6.9 & $6.6-7.2$ & 0.28 & $0.14-0.42$ \\
\hline & & Visit 2 & 3.3 & $3.1-3.5$ & 0.21 & $0.19-0.23$ \\
\hline & & Visit 3 & 6.2 & $6-6.4$ & 0.39 & $0.38-0.4$ \\
\hline & Intervention & Baseline & 7.1 & $6.8-7.5$ & 0.34 & $0.28-0.4$ \\
\hline & & Visit 2 & 1.9 & $1.6-2.3$ & 0.06 & $0.01-0.11$ \\
\hline & & Visit 3 & 1.7 & $1.6-1.9$ & 0.03 & $0.01-0.05$ \\
\hline \multirow[t]{6}{*}{$\mathrm{C}$} & Control & Baseline & 6.7 & $6-7.3$ & 0.41 & $0.33-0.47$ \\
\hline & & Visit 2 & 4.6 & $4.2-5.1$ & 0.10 & $0.01-0.27$ \\
\hline & & Visit 3 & 4.4 & $4.2-4.6$ & 0.21 & $0.16-0.3$ \\
\hline & Intervention & Baseline & 6.2 & $5.1-6.8$ & 0.48 & $0.45-0.51$ \\
\hline & & Visit 2 & 2.2 & $2-2.3$ & 0.12 & $0.07-0.17$ \\
\hline & & Visit 3 & 2.4 & $1.8-3.6$ & 0.13 & $0.01-0.21$ \\
\hline
\end{tabular}

